\title{
Maternal anthropometry as a predictor of birth weight
}

\author{
Shamsun Nahar ${ }^{1,2, *}$, CGN Mascie-Taylor ${ }^{1}$ and Housne Ara Begum ${ }^{1,3}$ \\ ${ }^{1}$ Department of Biological Anthropology, University of Cambridge, UK: ${ }^{2}$ National Institute for Preventive and Social \\ Medicine, Mohakhali, Dhaka 1212, Bangladesh: ${ }^{3}$ Institute of Health Economics, University of Dhaka, Dhaka, \\ Bangladesh
}

Submitted 5 July 2005: Accepted 14 February 2006

\begin{abstract}
Objective: To determine whether maternal anthropometry predicted birth weight, and if so, to identify which cut-offs provided the best prediction of low birth weight (LBW) in a field situation.

Design: Community-based longitudinal study.

Setting: A rural union of Bhaluka Upazila, Mymensingh, located $110 \mathrm{~km}$ north-west of Dhaka, the capital of Bangladesh.

Participants: A total of 1104 normotensive, non-smoking pregnant women who attended community nutrition centres were studied from first presentation at the centre until delivery of their child.

Results: Most of the pregnant mothers were between 20 and 34 years of age. Over one-third of the women were nulliparous, while $12.8 \%$ were multiparous (parity $\geq 4$ ). Most (93\%) mothers registered between the 3rd and 5th month of pregnancy. The frequency of LBW $(<2500 \mathrm{~g})$ was $17 \%$. Polynomial regression analyses showed that the best predictors of birth weight (based on adjusted $R^{2}$ values) were in general weight at registration and weight at month 9, with adjusted $R^{2}$ ranging from $2.5 \%$ to nearly $20 \%$. Sequential regression analyses with height and weight showed that there was a significant effect of height after removing the weight variables, and adjusted $R^{2}$ increased in all analyses. Weight and height at registration month continued to be the best predictors of LBW. Sensitivity and specificity curves were drawn for each registration month, body mass index and different weight gain groups, and using different weight and height combinations. The results showed that, for registration month 3-5, a combination of weight $(\leq 45 \mathrm{~kg})$ and height $(\leq 150 \mathrm{~cm})$ gave the highest sensitivity, which was $50 \%$. However, maternal weight $\leq 43 \mathrm{~kg}$ in pregnancy month 3-5 alone gave the highest sensitivity of $80 \%$.

Conclusion: The best predictor of birth weight as a continuous variable was maternal weight at registration, each $1 \mathrm{~kg}$ increase in weight at registration being associated with an increase in birth weight of about $260 \mathrm{~g}$. Maternal weight $\leq 43 \mathrm{~kg}$ in pregnancy month 3-5 alone gave the highest sensitivity of 80\%. A combination of initial weight and height of the mother was not as good a predictor of LBW as weight alone.
\end{abstract}

\author{
Keywords \\ Birth weight \\ Low birth weight \\ Predictor of low birth weight \\ Maternal anthropometry
}

Assessment of maternal nutritional status relies on measures of stature, pre-pregnancy weight (PPW), weight gain during pregnancy, weight gain at different trimesters, body mass index (BMI), height, skinfold thickness and limb circumferences. Some measures reflect a woman's nutritional status or energy stores as she enters pregnancy (height, PPW), while others reflect changes in her status over the course of pregnancy (skinfold thickness, limb circumference, pregnancy weight). Maternal weight, height and pregnancy weight gain have all been shown to be significant predictors of birth weight. Maternal nutrition status during pregnancy has been considered an important prognostic indicator of birth outcome ${ }^{1}$.

There are differences between developed and developing countries in determining the most appropriate cut-off points for anthropometric measurements ${ }^{2,3}$. Screening with measurements that require only one contact with a woman are useful due to limitations in the prenatal care available in developing countries. Numerous research projects ${ }^{4-7}$ have studied maternal anthropometric indicators as predictors of birth weight. However, fewer of them have focused on which is the best indicator in predicting birth weight with greater sensitivity, specificity and accuracy.

The present paper examines the relationship between birth weight and certain maternal anthropometric measurements and determines the sensitivity and specificity of these measures in predicting low birth weight (LBW).

\section{Participants and methods}

A 1-year, longitudinal, rural community-based study was conducted in Bhaluka Upazila, Mymensingh, which is 
located $110 \mathrm{~km}$ north-west of Dhaka, the capital of Bangladesh. Participants were pregnant women who registered at the community nutrition centre under the Bangladesh Integrated Nutrition Project between their 3rd and 6th month of gestation. A total of 1104 normotensive, non-smoking and non-morbid pregnant women were studied from first presentation at the community nutrition centre until delivery of their child. At first registration women were weighed and had their height measured; thereafter they had their weight measured at approximately monthly intervals.

All anthropometric measurements were carried out using standard methodology as described by Lohman et $a l^{8}$. The measurements were made with the participants wearing a minimum amount of clothing. Height was measured using a locally made stadiometer. The woman was asked to maintain an upright and erect posture with her feet together and the back of her heels touching the pole of the anthropometer. The horizontal headpiece was lowered onto the woman's head (maintained in the Frankfurt plane) and the measurement was taken to the nearest $0.1 \mathrm{~cm}$. The UNICEF UNI-Scale was used to measure the weight of the pregnant women and newborn babies. The weighing machine was calibrated with known weights up to $70 \mathrm{~kg}$ at the beginning of each weighing session. Newborn babies were weighed within $24 \mathrm{~h}$ of delivery at the birth place. The newborn was weighed without any clothes. Weights of the pregnant women and newborns were recorded to the nearest $0.1 \mathrm{~kg}$. Maternal BMI was calculated with the formula: weight $(\mathrm{kg}) /[\text { height }(\mathrm{m})]^{2}$.

Gestational age was assessed by the Parkin method, ${ }^{9}$ which scores four external characteristics: skin colour, skin texture, ear firmness and breast development. The scheme is simple, easy to use, less time-consuming and appropriate for fieldworkers. Ceesay et al. ${ }^{10}$ used this method in their Gambian study for calculating the gestational weeks in pregnancy. Newborns with gestational age $<37$ completed weeks were classified as preterm.

Weight of the pregnant women and newborns was recorded by four research assistants in their respective assigned areas in the community. The gestational scores were assessed by the research assistants as well as the first author.

The inter-observer error for height and weight were computed at four different times during the study: before starting the study, at the 5th and 9th months and at the end of the study. Ten subjects were used each time and the technical error of measurement (TEM) and reliability $(R)$ were determined. TEM was obtained from measurements of the same subject by each research assistant. Reliabilities for all measurements were above 0.98 and higher than the 0.95 threshold given by Ulijaszek and Kerr ${ }^{11}$. One of the problems with longitudinal data is that, in order to examine weight changes over time, the numbers of days between visits need to be very similar. Although this is potentially achievable in strictly research projects, in operational programmes this is much less likely to occur. Brush et al. ${ }^{12}$ overcame the monthly variation in days between measurements by computing the curvilinear relationship between the anthropometric variable, e.g. weight, and the actual days between measurements. As the polynomial fits (adjusted $R^{2}$ ) were very good, they calculated the weight at fixed intervals. The same procedure was used here because the 'monthly' variation in days was between 22 and 35 days. Consequently, individual polynomial regressions were computed for each woman and, as found by Brush et al., ${ }^{12}$ the fit was very good with adjusted $R^{2}$ ranging from over $95 \%$ to nearly $100 \%$. As a result, the predicted weight at 28 -day intervals was computed and these predicted weights were used in all the subsequent analyses.

\section{Results}

The anthropometric characteristics of the sample are shown in Table 1. Mean values (and standard deviations) of anthropometric measurements are presented both for the mothers and their newborn babies. Most of the pregnant mothers were between 20 and 34 years of age. Over one-third of the women were nulliparous, while $12.8 \%$ were multiparous (parity $\geq 4$ ). Most (93\%) mothers registered between the $3 \mathrm{rd}$ and 5 th month of pregnancy and only $7 \%$ registered in the 6th month.

\section{Prevalence of low birth weight and intrauterine growth retardation}

The World Health Organization defines LBW as $<2500$ g, and in the present sample about $17 \%$ fell into this category with almost equal numbers of LBW male (17\%) and female (16\%) babies. Gestational age was calculated for 327 newborns using the Parkin score. Of them 56 (17.1\%) were LBW, of whom 54 (96.4\%) were born after 37 weeks' gestation and the other two were born before 37 weeks' gestation. Thus intrauterine growth retardation (IUGR) appears to be the major contributor to LBW.

\section{Birth weight and relationship with maternal antbropometric variables}

To determine the relative importance of maternal anthropometric variables on birth weight, individual

Table 1 Anthropometric characteristics of the pregnant women and their newborn babies

\begin{tabular}{lr}
\hline Weight at registration $(\mathrm{kg})$ & $42.8(5.8)$ \\
Height $(\mathrm{cm})$ & $150.5(5.3)$ \\
Body mass index $\left(\mathrm{kg} \mathrm{m}^{-2}\right)$ & $18.9(2.2)$ \\
Weight at month $9(\mathrm{~kg})$ & $47.9(5.5)$ \\
Gestational weight gain $(\mathrm{kg})$ & $5.69(1.95)$ \\
Weight gain in second trimester $(\mathrm{kg})$ & $2.28(0.91)$ \\
Weight gain in third trimester $(\mathrm{kg})$ & $2.16(0.89)$ \\
Birth weight $(\mathrm{kg})$ & $2.69(0.36)$ \\
\hline
\end{tabular}

Data are presented as mean (standard deviation). 
polynomial regression analyses were undertaken using maternal height, weight and BMI at first registration, total weight gain in different registration months (month 3, month 4 , etc.), weight at month 9 of pregnancy, weight gains in the second and third trimesters, and monthly incremental weight gain. The best predictors of birth weight (based on adjusted $R^{2}$ ) were in general weight at registration and weight at month 9 (Table 2), with adjusted $R^{2}$ values ranging from $2.5 \%$ to nearly $20 \%$.

Sequential regression analyses were then used to test the impact of two variables, e.g. height and weight. The results are summarised in Table 3. In all analyses there was a significant effect of height after removing the weight variables, and adjusted $R^{2}$ increased in all analyses. Weight and height at registration month continued to be the best predictors of LBW.

\section{Sensitivity and specificity}

To predict LBW, specificity and sensitivity tests were performed with height, BMI, weight at registration for each registration month, weight gain, weight at month 9, and weight gain in the second and third trimesters. A good predictor is one which has a high sensitivity and high specificity. In this context, sensitivity is the ability to detect an LBW baby while specificity is the ability to detect a normal-birth-weight baby.

Sensitivity and specificity are dependent on one another; high sensitivity is required for the identification of all LBW babies. Unfortunately this leads to lowered specificity and a high false-positive rate, resulting in incorrect identification of women as high-risk. A high false-positive rate is not as serious as a high false-negative

Table 2 Regression analyses showing effect of mother's anthropometry on birth weight

\begin{tabular}{|c|c|c|c|c|c|}
\hline Variable & $A$ & $\beta$ & $F$ & $P$ & Adjusted $R^{2}$ \\
\hline \multicolumn{6}{|l|}{ Weight at registration } \\
\hline 3rd month & 2.00 & 0.017 & 28.71 & $<0.001$ & 5.4 \\
\hline 4th month & 1.66 & 0.024 & 36.40 & $<0.001$ & 11.3 \\
\hline 5th month & 1.55 & 0.026 & 29.34 & $<0.001$ & 15.0 \\
\hline 6th month & 1.36 & 0.028 & 18.36 & $<0.001$ & 19.6 \\
\hline \multicolumn{6}{|l|}{ Total weight gain } \\
\hline Registration month 3 & 2.28 & 0.066 & 48.83 & $<0.001$ & 8.9 \\
\hline Registration month 4 & 2.38 & 0.058 & 62.17 & $<0.001$ & 7.2 \\
\hline Registration month 5 & 2.38 & 0.070 & 81.53 & $<0.001$ & 7.8 \\
\hline Registration month 6 & 2.43 & 0.076 & 66.63 & $<0.001$ & 6.0 \\
\hline \multicolumn{6}{|l|}{$\begin{array}{l}\text { Body mass index at } \\
\text { registration }\end{array}$} \\
\hline 3rd month & 2.16 & 0.029 & 13.86 & $<0.001$ & 2.5 \\
\hline 4th month & 1.95 & 0.039 & 16.36 & $<0.001$ & 4.9 \\
\hline 5th month & 1.57 & 0.059 & 22.43 & $<0.001$ & 11.7 \\
\hline 6th month & 1.52 & 0.055 & 7.53 & 0.007 & 8.4 \\
\hline \multicolumn{6}{|l|}{ Other variables } \\
\hline Height & 0.83 & 0.012 & 33.41 & $<0.001$ & 3.1 \\
\hline Weight at month 9 & 1.49 & 0.025 & 163.88 & $<0.001$ & 13.7 \\
\hline $\begin{array}{l}\text { Weight gain in second } \\
\text { trimester }\end{array}$ & 2.55 & 0.063 & 19.07 & $<0.001$ & 2.2 \\
\hline $\begin{array}{l}\text { Weight gain in third } \\
\text { trimester }\end{array}$ & 2.49 & 0.094 & 55.73 & $<0.001$ & 5.1 \\
\hline
\end{tabular}

rate, i.e. failing to identify women at high risk, but it will burden any screening programme.

Sensitivity and specificity curves were drawn for each registration month, BMI and different weight gain groups, while sensitivity and specificity curves for weight at month 9 and weight gain in the second and third trimesters were undertaken on the whole sample.

The relationship between LBW and weight at registration month was quite similar for month 3 to month 5 and a weight of about $<43 \mathrm{~kg}$ provided $80 \%$ sensitivity (Fig. 1). However, in registration month 6 the same sensitivity would be achieved by a weight of about $\leq 49 \mathrm{~kg}$ (Fig. 2) and a similar weight predicts $80 \%$ of LBW babies at month 9 (Fig. 3). The relationship with BMI is similar to weight - a BMI of $\leq 19 \mathrm{~kg} \mathrm{~m}^{-2}$ predicts $80 \%$ sensitivity for registration months $3-5$ (Fig. 4), while a BMI of $\leq 22 \mathrm{~kg} \mathrm{~m}^{-2}$ is required in month 6 . The $80 \%$ sensitivity for weight gain is achieved at $\leq 7 \mathrm{~kg}$ for those mothers registering in month 3 , and at about $\leq 6 \mathrm{~kg}$, $\leq 5 \mathrm{~kg}$ and $\leq 4 \mathrm{~kg}$ for those registering in month 4 to 6 , respectively. A weight gain of $\leq 2.5 \mathrm{~kg}$ in the second or third trimesters is the cut-off for $80 \%$ sensitivity (Figs 5 and 6). Finally, a height of about $\leq 154 \mathrm{~cm}$ is required for the same sensitivity (Fig. 7).

Sensitivity and specificity were computed with combinations of different weights and heights taking the different weight cut-offs of $\leq 42 \mathrm{~kg}, \leq 43 \mathrm{~kg}, \leq 44 \mathrm{~kg}$ and $\leq 45 \mathrm{~kg}$ and height cut-offs of $\leq 145 \mathrm{~cm}, \leq 146 \mathrm{~cm}$, $\leq 147 \mathrm{~cm}, \leq 148 \mathrm{~cm}, \leq 149 \mathrm{~cm}$ and $\leq 150 \mathrm{~cm}$. Results showed that for registration month $3-5$, combination of weight $(\leq 45 \mathrm{~kg})$ and height $(\leq 150 \mathrm{~cm})$ gave the highest sensitivity, which was $50 \%$. However, $\leq 43 \mathrm{~kg}$ weight for month 3-5 in pregnancy alone gave the highest sensitivity of $80 \%$, which suggests that weight at pregnancy $\leq 43 \mathrm{~kg}$ is the best predictor of LBW.

\section{Discussion}

There are no adequate population-based studies of LBW in Bangladesh and the prevalence ranges from 20\% to $50 \%{ }^{13-17}$. This high variability of LBW may reflect differences between hospital- and field-based studies. However, a very recent hospital-based study in Bangladesh $^{18}$ reported $15 \%$ LBW, which is comparable to the $17 \%$ found in the present study. There are two main causes of LBW: being born small for gestational age (SGA) or being born prematurely. In developing countries, the majority of LBW infants are SGA but are not born prematurely. Nevertheless, $6.7 \%$ of LBW infants are born preterm in developing countries.

In the present study gestational age was calculated by using the Parkin score 9 and IUGR appeared to be the major contributor to LBW (96.4\%), with only 3.6\% being preterm. A study in India among the Bengali newborn found that less than $10 \%$ of LBW infants were preterm ${ }^{19}$. The contribution of IUGR to LBW in the developing world 
Table 3 Regression analyses showing the simultaneous effect of using two anthropometric variables on birth weight

\begin{tabular}{|c|c|c|c|c|c|c|c|c|c|c|}
\hline \multirow[b]{2}{*}{ Variable } & \multicolumn{2}{|c|}{$A$} & \multicolumn{2}{|c|}{$\beta$} & \multicolumn{2}{|c|}{$F$} & \multicolumn{2}{|c|}{$P$} & \multicolumn{2}{|c|}{ Adjusted $R^{2}$} \\
\hline & Weight & Height & Weight & Height & Weight & Height & Weight & Height & Weight & Height \\
\hline \multicolumn{11}{|l|}{ Weight at registration } \\
\hline 3rd month weight \& height & 2.00 & 1.41 & 0.115 & 0.004 & 28.77 & 1.63 & $<0.001$ & NS & 5.4 & 5.5 \\
\hline 4th month weight \& height & 1.66 & 0.95 & 0.022 & 0.005 & 39.23 & 1.20 & $<0.001$ & NS & 11.3 & 11.6 \\
\hline 5th month weight \& height & 1.55 & 2.08 & 0.028 & 0.004 & 29.34 & 0.50 & $<0.001$ & NS & 15.0 & 15.2 \\
\hline 6th month weight \& height & 1.36 & -0.26 & 0.022 & 0.013 & 18.36 & 1.68 & $<0.001$ & NS & 19.6 & 20.4 \\
\hline \multicolumn{11}{|l|}{ Total weight gain } \\
\hline Registration month 3 & 2.28 & 1.07 & 0.063 & 0.008 & 48.84 & 6.93 & $<0.001$ & 0.009 & 8.9 & 10.0 \\
\hline Registration month 4 & 2.38 & 0.99 & 0.054 & 0.009 & 62.17 & 15.72 & $<0.001$ & $<0.001$ & 7.2 & 8.9 \\
\hline Registration month 5 & 2.38 & 1.06 & 0.066 & 0.009 & 81.53 & 17.07 & $<0.001$ & $<0.001$ & 7.8 & 9.3 \\
\hline Registration month 6 & 2.44 & 0.85 & 0.071 & 0.011 & 66.64 & 25.97 & $<0.001$ & $<0.001$ & 6.0 & 8.3 \\
\hline \multicolumn{11}{|l|}{ Other variables } \\
\hline Weight at month 9 \& height & 1.49 & 1.31 & 0.024 & 0.001 & 163.83 & 0.38 & $<0.001$ & NS & 13.7 & 13.7 \\
\hline Weight gain in second trimester \& height & 2.55 & 0.93 & 0.058 & 0.011 & 19.07 & 20.94 & $<0.001$ & $<0.001$ & 2.2 & 4.6 \\
\hline Weight gain in third trimester \& height & 2.49 & 0.83 & 0.88 & 0.011 & 55.73 & 27.85 & $<0.001$ & $<0.001$ & 5.1 & 7.5 \\
\hline
\end{tabular}

NS - not significant.

and the actual levels of IUGR are not always possible to assess from field studies. A hospital-based study in Bangladesh $^{15}$ reported that $27 \%$ of babies were born LBW, of which only $16 \%$ were preterm. This would make IUGR the contributing factor to $84 \%$ of LBW babies. Another study in a Dhaka slum in Bangladesh ${ }^{20}$ found that, of 1654 newborns, 46.4\% weighed <2500 g, 70\% were SGA or IUGR, and $17 \%$ were premature. As the subjects in that study were from a slum, their lifestyle and physical activities were different from the rural pregnant women we studied and may contribute to the higher rate of premature babies.

Several studies have reported that mothers who have a PPW of $<40 \mathrm{~kg}$ have a three-fold greater risk of having an LBW baby than mothers with PPW $>40 \mathrm{~kg}^{6,21,22}$, and a PPW cut-off of $40 \mathrm{~kg}$ is the most commonly cited figure in developing countries used to assess risk of various pregnancy outcomes. Ideally, PPW should be taken before the woman is diagnosed as pregnant. However, this is very difficult especially in developing countries and most studies use measurements early in pregnancy as a

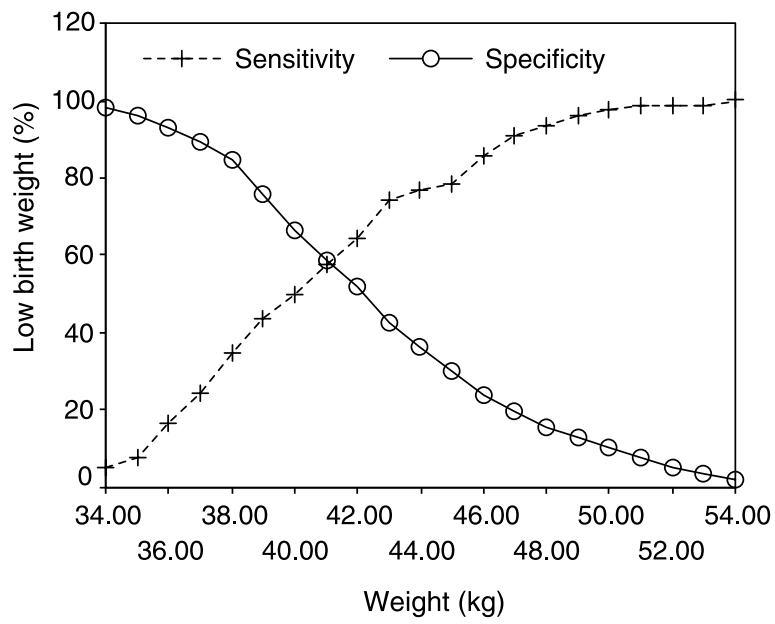

Fig. 1 Sensitivity and specificity for weight at registration month 3 proxy for pre-pregnancy status. An Indian study ${ }^{6}$ assumed no weight gain up to 13 weeks' gestation, because they found that women do not gain much weight in this period.

A meta-analysis of 25 studies $^{23,24}$ of maternal anthropometry from 20 countries, involving over 111000 births worldwide, revealed that attained weight during pregnancy was strongly associated with birth weight and intrauterine growth. Weight gain monitoring in pregnancy may not be feasible for many developing countries at the current time due to limited coverage of antenatal care.

Tripathi et al. ${ }^{6}$ showed the importance of attained weight for predicting birth weight based on their work in Varanasi, India. The advantage of using a standard for attained weight at a specific point in pregnancy is that it requires a single measurement only. Several cut-off points have been recommended in the literature. Karan and Mathur $^{25}$ found that rural Indian women who weighed $<40 \mathrm{~kg}$ at some point in pregnancy delivered infants with the lowest birth weight, while women who weighed $\leq 45 \mathrm{~kg}$ also delivered significantly more LBW babies than those who weighed $>45 \mathrm{~kg}$ at some point in pregnancy.

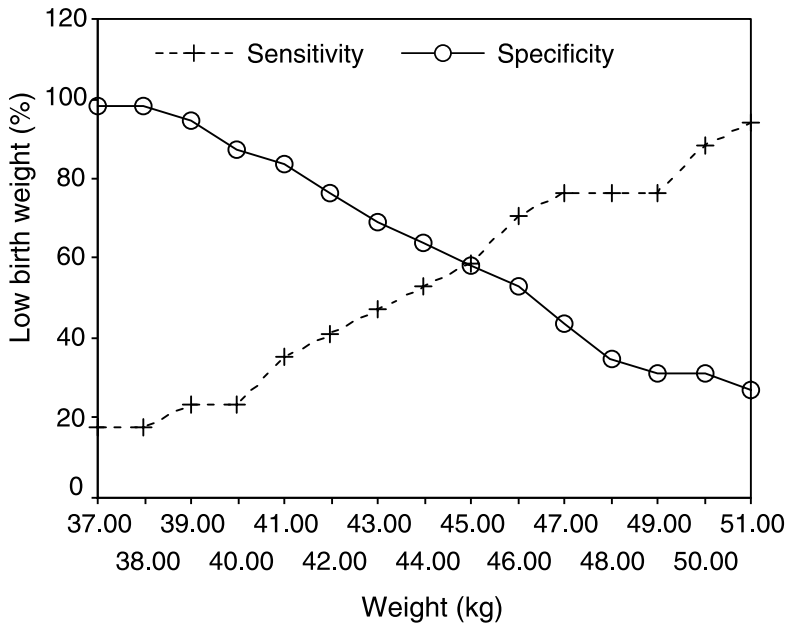

Fig. 2 Sensitivity and specificity for weight at registration month 6 


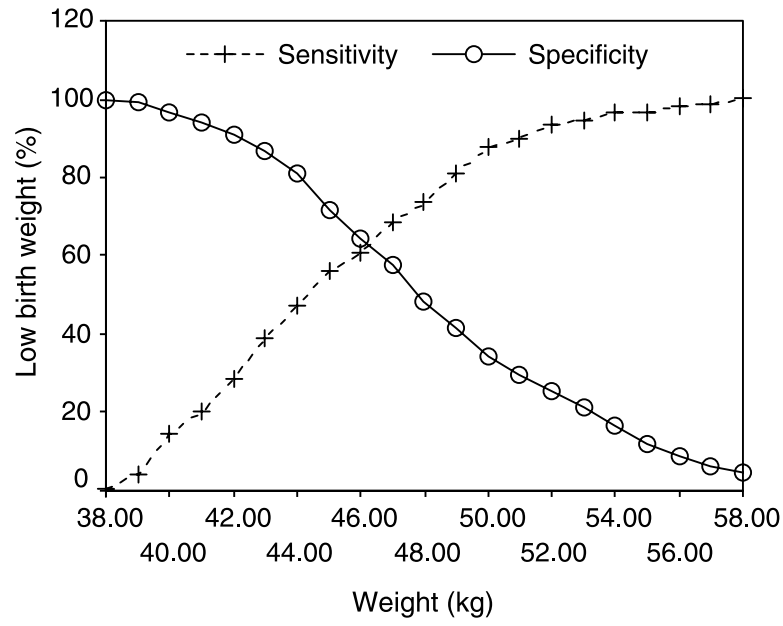

Fig. 3 Sensitivity and specificity for weight at month 9

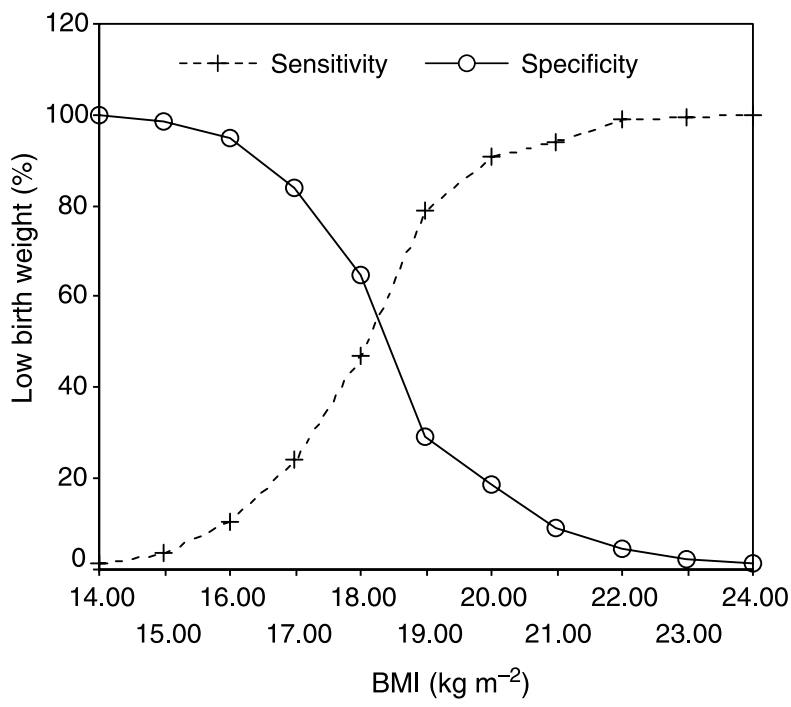

Fig. 4 Sensitivity and specificity for body mass index (BMI) at registration month 3

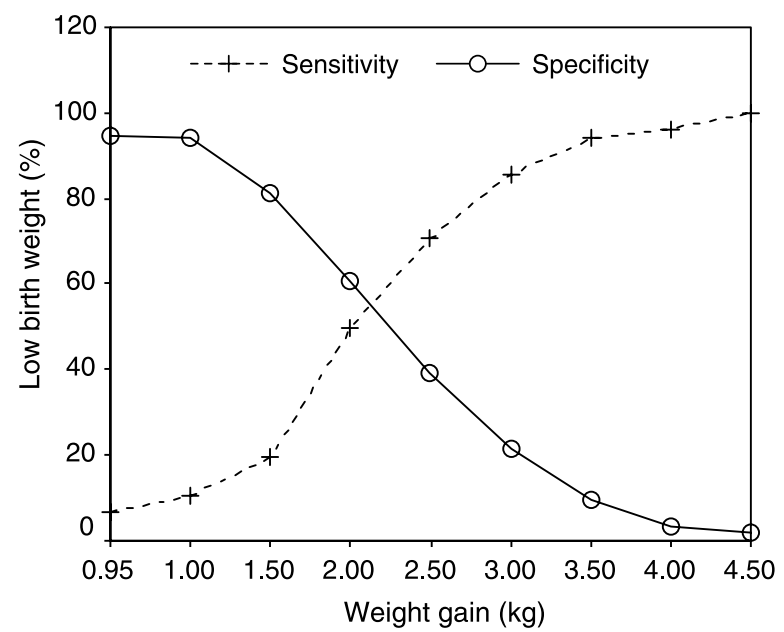

Fig. 5 Sensitivity and specificity for weight gain in the second trimester

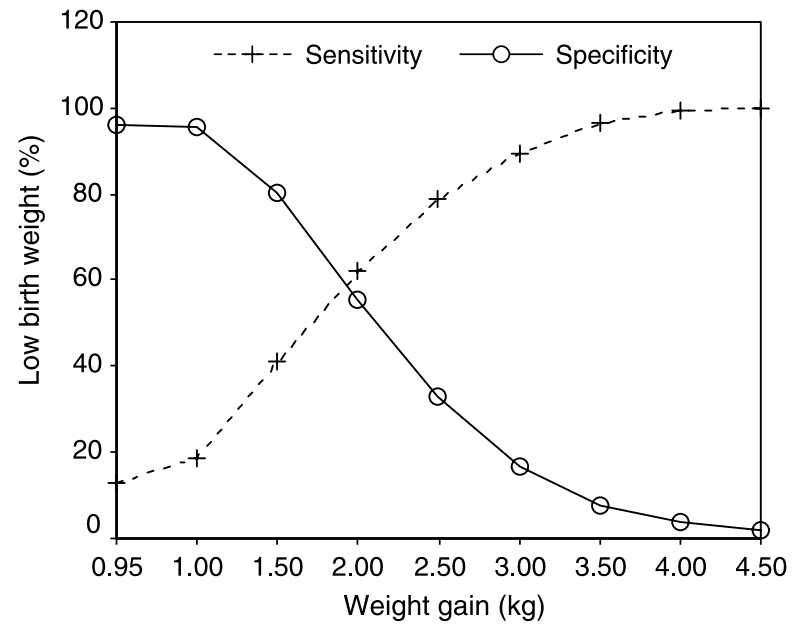

Fig. 6 Sensitivity and specificity for weight gain in the third trimester

Tripathi et al. ${ }^{6}$ suggested a cut-off of $45 \mathrm{~kg}$ at 13 weeks, increasing to $47 \mathrm{~kg}$ at 20 weeks, $49 \mathrm{~kg}$ at 25 weeks, $50 \mathrm{~kg}$ at 30 weeks, $51 \mathrm{~kg}$ at 35 weeks and $52 \mathrm{~kg}$ at 40 weeks. Other recommendations for cut-off values are $<40 \mathrm{~kg}$ at 20 weeks ${ }^{26}$ and $<42 \mathrm{~kg}$ at 24 or 32 weeks, ${ }^{27}$ also based on work in India.

In the present study, sensitivity and specificity of LBW were examined for maternal weight at registration, weight gain in pregnancy, BMI, weight at month 9 and weight gain in the second and third trimesters, and for height and height and weight combined. The analyses suggested that $\leq 43 \mathrm{~kg}$ weight at registration month 3-5 of pregnancy provided high sensitivity (about 80\%) for predicting LBW. Furthermore, a combination of weight and height did not improve sensitivity. Other measures such as weight at month 9 also had high sensitivity, but from a programmatic point of view this has very limited value. What was very clear from the

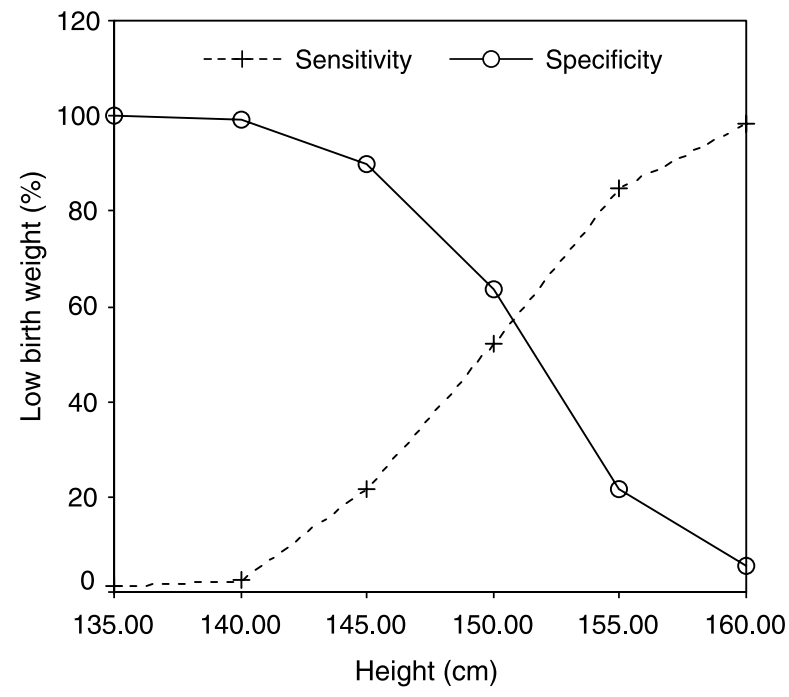

Fig. 7 Sensitivity and specificity for height 
analyses was that BMI and height and weight combined had poorer prediction than weight alone.

In conclusion, the best predictor of birth weight as a continuous variable was maternal weight at registration each $1 \mathrm{~kg}$ increase in weight at registration was associated with about $200 \mathrm{~g}$ increase in birth weight; initial weight of $\leq 43 \mathrm{~kg}$ predicted $80 \%$ or more of LBW babies for registration month $3-5$ but at registration month 6 it would have to be much higher, $\leq 49 \mathrm{~kg}$, for the same sensitivity; and a combination of initial weight and height of the mother was not as good a predictor of LBW as weight alone.

\section{Acknowledgements}

We thank all participants and staff of the Bangladesh Integrated Nutrition Project. This work was supported by The British Council and the University of Cambridge, UK.

\section{References}

1 Merchant SS, Momin IA, Sewani AA, Zuberi NF. Effect of prepregnancy body mass index and gestational weight gain on birth weight. Journal of the Pakistan Medical Association 1999; 49: 23-5.

2 Kramer M. Determinants of low birth weight: methodological assessment and meta-analysis. Bulletin of the World Health Organization 1987; 65: 663-737.

3 Shah K. The evolution of the use of arm circumference for assessing maternal nutritional status. In: Krasovec K, Anderson MA, eds. Maternal Nutrition and Pregnancy Outcomes. Anthropometric Assessment. PAHO Scientific Publication No. 529. Washington, DC: Pan American Health Organization, 1991; 132-7.

4 Naeye R. Weight gain and the outcome of pregnancy. American Journal of Obstetrics and Gynecology 1979; 135 3-9.

5 de Siqueira AAF, Junior CC, Marcondes De Almeida PA, Tanaka ACd'A, Montelone PPR, et al. The influence of maternal height and weight gain and gestational age on the newborn's weight. Revista de Saúde Pública 1975; 9: $331-42$.

6 Tripathi AM, Agarwal DK, Devi RR, Cherian S. Nutritional status of rural pregnant women and fetal outcome. Indian Pediatrics 1987; 24: 703-12.

7 Winikoff B, Debrovner C. Anthropometric determinants of birth weight. Obstetrics and Gynecology 1981; 58: 678-84.

8 Lohman TG, Roche AF, Martorell R. Anthropometric Standardization Reference Manual. Champaign, IL: Human Kinetics Books, 1988.

9 Parkin JM, Hey EN, Clowes JS. Rapid assessment of gestational age at birth. Archives of Disease in Childhood 1976; 51: 259-63.

10 Ceesay SM, Prentice AM, Cole TJ, Foord F, Weaver LT, Poskitt EM, et al. Effects on birth weight and perinatal mortality of maternal dietary supplements in rural Gambia: 5 year randomised controlled trial. British Medical Journal 1997; 315: 786-90.

11 Ulijaszek SJ, Kerr DA. Anthropometric measurement error and the assessment of nutritional status. British Journal of Nutrition 1999; 82: 165-77.

12 Brush G, Harrison GA, Barber FM, Zumrawi FY. Comparative variability and interval correlation in linear growth of Hong Kong and Sudanese infants. American Journal of Human Biology 1992; 17: 291-9.

13 Canosa CA. Intrauterine growth retardation in India and Bangladesh. In: Intrauterine Growth Retardation. Nestlé Nutrition Workshop Series No. 18. New York: Raven Press, 1989; 183-204.

14 United Nations Children's Fund. The State of the World's Children. Washington, DC: The World Bank, 1991.

15 Ahmed FU, Das AM, Mostafa M, Begum S. The Distribution of Birth Weight in an Urban Maternity Center of Bangladesh. Dhaka, Bangladesh, UNICEF, 1992.

16 Karim E, Mascie-Taylor CGN. The association between birth weight, sociodemographic variables and maternal anthropometry in an urban sample from Dhaka, Bangladesh. Annals of Human Biology 1997; 24: 387-401.

17 Nahar N, Afroza S, Hossain M. Incidence of low birth weight in three communities in Bangladesh. Bangladesh Medical Research Council Bulletin 1998; 18: 157-64.

18 Dhar B, Mowlah G, Kabir D. Newborn anthropometry and its relationship with maternal factors. Bangladesh Medical Research Council Bulletin 2003; 29: 48-58.

19 Pakrasi K, Sil S, Dasgupta P, Dasgupta I. Patterns of low birth weight in the Bengali newborns. Indian Journal of Physical Anthropology and Human Genetics 1985; 11: 107-22.

20 Arifeen SE, Black RE, Caulfield LE, Antelman G, Baqui AH, Nahar Q, et al. Infant growth patterns in the slums of Dhaka in relation to birth weight, intrauterine growth retardation, and prematurity. American Journal of Clinical Nutrition 2000; 72: 1010-7.

21 Kardjati S, Kusin JA, de With C. Energy supplementation in the last trimester of pregnancy in East Java: I. Effect on birthweight. British Journal of Obstetrics and Gynaecology 1988; 95: 783-94.

22 Esguerra AB, Diamante AN, Ramos MM Jr, Doctor VS, Valdes CB, Pagorogon RR et al. Concise screening scales for high-risk mothers and newborns. In: Del Mundo F, Ines-Cuyegkeng E, Aviado DM eds, Primary Maternal and Neonatal Health: A Global Concern. New York: Plenum Press, 1983, 347-69.

23 Kelly A, Kevany J, de Onis M, Shah PM. A WHO Collaborative Study of Maternal Anthropometry and Pregnancy Outcomes. International Journal of Gynaecology and Obstetrics 1996; 53: 219-33.

24 Anon. Can maternal height and weight be used to predict pregnancy outcome? SafeMotherhood 1996; 22: 10-1.

25 Karan S, Mathur BC. Risk factors in mothers and newborn. Indian Pediatrics 1987; 54: 35-40.

26 Shah KP, Shah PM. Relationship between weight during pregnancy and birth weight. Indian Pediatrics 1972; 9: 526-31.

27 Shah K. Survival card for married women for better obstetric performance. Journal of Obstetrics and Gynaecology of India 1978; 28: 1015-20. 